\title{
DINÂMICAS DA AÇÃO COLETIVA NO BRASIL CONTEMPORÂNEO: encontros e desencontros entre o sindicalismo e a juventude trabalhadora
}

\author{
Ruy Braga * \\ Marco Aurélio Santana * *
}

\begin{abstract}
Tendo em vista o lugar tradicional dos sindicatos como canal de organização e condução de conflitividade na sociedade brasileira, o artigo se propõe articular a reconfiguração das classes sociais no Brasil contemporâneo, as manifestações atuais da inquietação social e a situação dos sindicatos frente a essa nova configuração. A especial ênfase ao papel dos sindicatos nesta nova conjuntura global parte da premissa de que as diferentes respostas dos sindicatos nacionais ao advento do protagonismo político da juventude trabalhadora em condições precárias de vida e de trabalho representam uma oportunidade privilegiada de observação das atuais reconfigurações classistas em contextos de crise.
\end{abstract}

Palavras-Chave: Trabalho. Trabalhadores. Juventude. Sindicatos. Ação Coletiva.

\section{APRESENTAÇÃO}

Enquanto as manifestações de junho de 2013 faziam tremer a nação, uma pergunta pairava no ar: diante de tantos protestos e mobilizações, onde os jovens davam a tônica, por que os sindicatos não contavam entre as forças motoras daquele mar revoltoso de gente? Aumentando o vazio da ausência dos mesmos no cenário, uma greve geral foi convocada, pelas redes sociais, sem que eles, como outrora, protagonizassem a convocação. Quando, finalmente, apareceram em cena, quase em resposta alternativa àquele chamamento, no dia nacional de lutas, pareciam um tanto em descompasso quantitativo e qualitativo com tudo o que se passava.

A partir do que seria esta disjuntiva, poder-se-ia pensar o lugar tradicional dos sindicatos como canal de organização e condução de conflitividade na sociedade brasileira. Pro-

* Universidade de São Paulo. Faculdade de Filosofia Letras e Ciências Humanas. Departamento de Sociologia.

Av. Prof. Luciano Gualberto, 315. Cep: 05508-010. Butantã - São Paulo - SP - Brasil. ruy.braga@uol.com.br

** Universidade Federal do Rio de Janeiro. Instituto de Filosofia e Ciências Sociais. Departamento de Sociologia. Largo de São Francisco, 1, Sala 418. Cep: 20051070. Centro - Rio de Janeiro, RJ - Brasil. msantana@ifcs.ufrj.br pomo-nos a fazer isso a partir de um eixo que articula a reconfiguração das classes sociais no Brasil contemporâneo, as manifestações atuais da inquietação social e a situação dos sindicatos frente a essa nova configuração. A especial ênfase ao papel dos sindicatos nesta nova conjuntura global parte da premissa de que as diferentes respostas dos sindicatos nacionais ao advento do protagonismo político da juventude trabalhadora em condições precárias de vida e de trabalho - o precariado ${ }^{1}$ - representam uma oportunidade privilegiada de observação das atuais reconfigurações classistas em contextos de crise.

\section{UM OLHAR SOBRE O TRABALHO GLOBAL: precarização e contramo- vimentos}

Já de algum tempo, muitos analistas têm apontado, sistematicamente, para um enfra-

${ }^{1}$ Conforme, entre outros, Standing (2012 e 2013), seria o grupo de trabalhadores que transitam rapidamente pelo mercado de trabalho (intermitentes, temporários, terceirizados etc.), jovens trabalhadores à procura do primeiro emprego, que estão na informalidade, imigrantes, além de sub-remunerados e inseridos em condições degradantes de trabalho. Uma população que cresceu muito desde a década de 1990, tanto na Europa, como no Brasil. Ver, para mais detalhes, Braga (2012 e 2015). 
quecimento do sindicalismo fordista apoiado na fração adulta, branca, masculina e nacional da classe trabalhadora dos países de capitalismo avançado (Beaud e Pialoux, 2009, entre outros). A mudança da estrutura industrial dos países do Norte global para os países do Sul global ${ }^{2}$ (especialmente, a China) somada ao enfraquecimento da segurança sócio-ocupacional, promovido tanto pela retração dos direitos trabalhistas quanto pelo declínio do apoio de governos liderados por partidos social-democratas teriam decretado o advento de toda uma era de declínio do poder sindical em escala global, traduzido em queda nas taxas de sindicalização e na perda de influência política em escala nacional.

Tendo em vista a acentuada transformação na correlação global de forças entre as classes estabelecida no pós-guerra e nos novos desafios enfrentados pelo poder sindical, a partir dos anos 1980, alguns estudiosos do trabalho decidiram analisar as respostas produzidas pelas forças sociais do trabalho aos desafios da globalização neoliberal, privilegiando uma perspectiva desigual e combinada do fenômeno sindical, por meio de estudos comparativos entre diferentes realidades nacionais (Bieler, 2014; Bieler, Ciccaglione, Hilary e Lindberg, 2014; Harriss, 2010, dentre outros).

Deslocando o foco das estratégias sindicais balizadas exclusivamente pelo EstadoФั nação para as mudanças na ação coletiva das forças sociais do trabalho, tendo em vista proF cessos emergentes de solidariedade transna-

Aqui, vale dizer que, em geral, acompanhamos aqueles

If que ution capitalistas periféricas e semi-periféricas do atual

J sistema internacional estratificado e hierarquizado, cujos

ritmos de transformação social e exploração econômica

diferem mais ou menos acentuadamente dos países locali-

zados metaforicamente no "Norte global". Para mais deta-

Ihes, ver Santos (2007). tais como os trabalhadores informais e os trabalhadores precarizados (Agarwala, 2013), além das estratégias transnacionais do movimento sindical fordista (Evans, 2014). ${ }^{3}$

De uma maneira geral, estes novos estudos do trabalho global, apesar de seu relativo subdesenvolvimento e de sua acentuada diversidade temática, compartilham uma perspectiva mais ou menos comum, segundo a qual a velha regulação fordista não é mais hegemônica e a nova regulação pós-fordista, (des) construída pela globalização capitalista, é, em essência, despótica, isto é, refratária ao poder sindical. Daí a ênfase nos novos parâmetros da organização do trabalho e nos novos repertórios de ação coletiva (Munck, 2002), capazes de esboçar um "contramovimento polanyiano" (Silver, 2003) à privatização, à mercantilização e à liberalização do trabalho. ${ }^{4}$

No entanto, e este é um traço marcante destes novos estudos do trabalho, ao contrário do que ocorreu logo após o sucesso das manifestações contra o encontro da Organização Mundial do Comércio (OMC) em Seattle, em 30 de novembro de $1999,{ }^{5}$ quando alguns estudiosos do trabalho passaram a destacar a arena global, em detrimento do contexto nacional, como prioritária para apreender a renovação das dinâmicas da ação coletiva do trabalho (Waterman, 2001), ${ }^{6}$ os novos estudos do traba-

3 Sobre a importância da imbricação entre novas formas de ativismo, ação coletiva internacional e sindicalismo de movimento social, ver, também, Moody (1997a).

${ }^{4}$ Para Polanyi (2000), a autonomização das relações mercantis de seu contexto social é sempre enfrentada pela sociedade que busca enraizá-las novamente nas relações sociais por meio de "contramovimentos" à "commodificação" das três mercadorias fictícias, isto é, o trabalho, a terra e o dinheiro. O Estado encontra-se entre estes dois polos, desempenhando um papel-chave tanto na promoção de políticas que fortalecem o mercado, quanto na proteção da sociedade contra as ameaças da mercantilização.

${ }^{5}$ Nesta ocasião, cerca de 100 mil ativistas de diferentes movimentos sociais, em especial, ecologistas, anarquistas, trabalhadores sindicalizados e estudantes mobilizaram-se por vários dias nas ruas de Seattle até conseguirem o bloqueio da chamada "Rodada do Milênio".

${ }^{6}$ Para alguns analistas, após a "batalha de Seattle", o sindicalismo estaria adotando um modelo de sindicalismo de movimentos sociais apoiado em estratégias de ação direta e formas organizativas horizontalizadas, balizadas por campanhas contra instituições do poder global (desde grandes corporações e bancos, até organizações multilaterais, como a OMC, por exemplo). Foi o período marcado 
lho enfatizam a centralidade da relação entre os contextos global e nacional, a fim de compreender as questões emergentes do trabalho na globalização (Evans, 2014).

De fato, após o advento da crise econômica internacional, em 2008, e o relativo malogro das coalizões globais entre sindicatos, organizações não-governamentais (ONGs), agrupamentos de esquerda e movimentos sociais, inspirados na experiência de Seattle, os estudos do trabalho adentraram um período de certa polarização entre aqueles que seguiram enfatizando a importância de uma mudança de escala nas análises do trabalho com foco nas dinâmicas globais (Waterman, 2008) e aqueles um tanto ou quanto céticos em relação à importância da dimensão global na explicação dos movimentos trabalhistas (Seidman, 2008; Burawoy, 2010a).

Entre estes dois polos, organizou-se um campo investigativo que, além de destacar a centralidade da escala nacional, em especial, a relação entre o Estado e os movimentos trabalhistas, na estruturação da escala global, tem buscado compreender o fenômeno da transnacionalização do trabalho a partir de uma posicionalidade sociológica enraizada no chamado Sul global. Assim, estes estudos objetivam construir uma análise mais apurada dos entraves erguidos por coalizões nacionais dominadas pelo capital financeiro globalizado aos projetos de construção de formas de solidariedade trabalhista em escala internacional (Chibber, 2007).

Mesmo reconhecendo que as condições gerais criadas pela globalização neoliberal a partir dos anos 1980 continuam centrais para a compreensão das dinâmicas do mundo do trabalho, estes novos estudos compreendem que a arquitetura geral da solidariedade do trabalho global depende de como as estratégias nacionais são mutuamente combinadas. Neste sentido, o foco destes estudos recaiu sobre as conexões reais - e potenciais - entre diferen-

pela emergência dos chamados estudos do "novo internacionalismo operário” (Santos e Costa, 2004). tes movimentos de trabalhadores nacionais. E, para tanto, tais estudos desenvolveram uma ênfase comparativa entre múltiplos contextos nacionais, a fim de explorar a relação desigual e combinada existente entre os ritmos da (re) organização das classes trabalhadoras nacionais na globalização capitalista (Webster, Lambert, Bezuidenhout, 2008).

Outra preocupação compartilhada pelos diferentes estudos do trabalho global é a revalorização da análise de Polanyi (2000) acerca do fundamentalismo de mercado. Assim como ele, os analistas atuais têm destacado a centralidade da sociedade civil como barreira ao avanço tanto da mercantilização quanto da burocratização do trabalho. Para tanto, estes estudos usualmente resgatam três conceitos-chave da obra polanyiana: os conceitos de mercadorias fictícias (isto é, o trabalho, a terra e o dinheiro ${ }^{7}$ ), de mercantilização e de contramovimento. A partir daí, argumentam os analistas, seria possível problematizar, de forma mais frutífera, a relação entre os desdobramentos da crise atual - tais como o avanço do desemprego, da imigração de trabalhadores, da segregação do espaço urbano etc. - e as respostas associativas dos trabalhadores aos desafios impostos pela globalização capitalista.

Para Burawoy, por exemplo, a atualização da obra polanyiana permitiria uma identificação mais precisa das diferentes dimensões da desigualdade, em especial, a desigualdade pensada como exclusão social - como, por exemplo, o desemprego, a espoliação de terras, a imigração, etc. - e a desigualdade entendida como inclusão desigual - casos da precarização do trabalho, do subemprego, da segregação do espaço urbano etc. (Burawoy, 2010). Além disso, a partir de Polanyi, seria possível analisar, por meio da comparação entre diferentes processos nacionais de mercantilização (do trabalho, da terra e do dinheiro), a relação de-

${ }^{7}$ Polanyi (idem) argumenta que o trabalho, a terra e o dinheiro não deveriam ser comprados ou vendidos, pois isso acarretaria uma mercantilização desregulada, que destruiria seu caráter de fatores essenciais de produção. Para mais detalhes, ver nota 4 . 
sigual e combinada entre a exclusão social e a inclusão desigual.

Assim, a reconstrução teórica da obra de Polanyi adquire especial importância no atual momento, marcado pela precarização como (sub)proletarização promovida pelo avanço das políticas de austeridade na Europa ocidental e pela expulsão das classes médias tradicionais para fora do modelo de desenvolvimento pósfordista globalizado (Estanque, Costa, Soeiro, 2013). De fato, o tempo presente aprofunda as tensões entre a forma democrática dos regimes políticos e a dimensão autoritária de seu conteúdo econômico. Esta tensão tem estimulado diferentes movimentos sociais de contestação (Occupy Wall Street, "15-M", "Que se Lixe a Troika!” etc.) à atual globalização capitalista, lembrando o alvorecer daqueles contramovimentos de resistência aos avanços da mercantilização descritos por Polanyi para o período do entre-guerras. Neste sentido, estes novos movimentos sociais, protagonizados por jovens trabalhadores desempregados - ou subempregados -, condensam respostas à separação entre o poder econômico e a participação democrática.

À tensão social produzida pela separação entre o poder econômico e a participação democrática, devemos acrescentar a desigualdade econômica crescente entre classes so- papel-chave na interpretação do atual ciclo de mobilizações do jovem precariado global. Segundo Burawoy (2010, p. 20), "No processo de venda da força de trabalho, a "precariedade' e a insegurança laboral tornaram-se as experiências dominantes de partes cada vez maiores da população, tanto que Guy Standing (2011) argumenta que o precariado substituiu o proletariado". De fato, a mercantilização do trabalho tem se mostrado tanto uma fonte de precarização da condição proletária como de estímulo ao surgimento de contramovimentos sociais em escala nacional e transnacional. $\mathrm{Ou}$ seja, trata-se de um processo que desafia teórica e empiricamente os estudos do trabalho global. No entanto, é importante não perder de vista que, apesar da interconexão global e da mútua influência, os contramovimentos de trabalhadores precários são plasmados, sobretudo, pelo terreno político nacional. ${ }^{8}$

De qualquer maneira, uma agenda de estudos do trabalho global parece estar se consolidando em torno das relações entre os avanços da mercantilização do trabalho, da terra e do dinheiro em escala global e as diferentes respostas em termos de automobilização dos trabalhadores. Nestes termos, é possível identificar um decidido investimento destes estudos na análise dos novos repertórios, mobilizados pelas forças sociais do trabalho, no sentido de enfrentar o avanço transnacional da desconstrução das formas tradicionais de solidariedade fordista e do enfraquecimento do poder sindical (Tait, 2005). Daí a recorrência de pesquisas que buscam destacar a formação de novas coalizões entre os sindicatos fordistas e os trabalhadores precarizados, além da criação de redes sindicais internacionais (Evans, 2010; Harrod e O'Brien, 2002, dentre outros).

Assim, uma série de questões tem estimulado o desenvolvimento da agenda dos estudos do trabalho global. Dentre as mais frequentes, destacam-se: que papel o movimento dos

${ }^{8}$ Aliás, as dificuldades de construir laços globais de solidariedade entre estes movimentos é algo reconhecido por diferentes analistas (Nowak e Gallas, 2014) 
trabalhadores no Sul global pode cumprir na construção de uma nova arquitetura do trabalho em escala mundial? Que relação esta nova arquitetura do trabalho poderá estabelecer com os movimentos sociais enraizados nacionalmente? Qual a importância da dialética entre as conexões transnacionais e os movimentos sindicais nacionais para a análise da mobilização social dos trabalhadores precarizados? Se a globalização neoliberal não foi capaz de prevenir totalmente novas conexões entre diferentes movimentos dos trabalhadores, como mudanças econômicas e políticas nacionais podem promover alianças sindicais transnacionais?

Apoiando-se nestas preocupações, alguns analistas têm buscado adiantar respostas por meio da análise da recente experiência da classe trabalhadora brasileira. Dentre eles, destaca-se Peter Evans, cujo foco investigativo incide sobre as mudanças estruturais da economia globalizada que têm facilitado uma utilização sinérgica de diferenças nacionais em benefício de campanhas internacionais. Para Evans, o relativo declínio econômico do Norte global, em especial, dos Estados Unidos, somado aos ataques aos direitos sociais e trabalhistas estimulou o aparecimento de novas estratégias transnacionais no movimento sindical estadunidense.

A ascensão econômica e política do Sul global, por sua vez, teria levado o movimento dos trabalhadores, em alguns países como o Brasil, por exemplo, a alargar suas orientações estratégicas, ultrapassando as fronteiras nacionais. Além disso, a globalização de empresas capitalistas baseadas no país acrescentou incentivos outrora semeados pela longa predominância das corporações transnacionais, fazendo com que o movimento sindical brasileiro se tornasse ainda mais aberto às conexões com outros movimentos sindicais nacionais.

Em suma, uma abordagem do movimento dos trabalhadores hoje, focada exclusivamente no nível global, será sempre parcial e enganadora. O mesmo pode ser dito a respeito daqueles que não atribuem importância à escala global na reconfiguração das forças sociais do trabalho. Ou seja, o potencial para sinergias positivas, criado pelas diferenças nacionais, merece nossa atenção. ${ }^{9}$ Além disso, ao investigarmos a multiplicidade de caminhos por meio dos quais os movimentos sociais e sindicais podem se conectar uns com os outros, poderemos incrementar as teorias sobre a evolução da contestação das forças sociais do trabalho ao capital globalizado. ${ }^{10}$

De fato, o sindicalismo brasileiro tem demonstrado certo vigor em termos de experiências de internacionalização. O caso da participação da Central Única dos Trabalhadores (CUT) nas campanhas das Federações Sindicais Globais (GUFs) analisado por Evans (2014), ${ }^{11}$ por exemplo, além da criação da Rede Internacional Sindical de Solidariedade e Lutas pela Central Sindical e Popular (CSP-Conlutas) permitem aferir esta afirmação. Além disso, desde 2008, o movimento sindical brasileiro tem protagonizado uma onda de greves e paralisações, com expressivos resultados salariais, comparável em termos de jornadas paradas apenas àquela do final da década de 1980 e início dos anos 1990 (Dieese, 2013a e 2013b). Este vigoroso apetite grevista demonstra que, ao contrário da tendência declinante verificada nos países do Norte global, o sindicalismo brasileiro segue ativo como em poucos momentos de sua história recente.

No tocante ao atual ciclo grevista no país, é notável o crescimento de $227 \%$ do número de greves, nos setores público e privado, segunda dados do DIEESE, em 2013 (2000) em relação ao ano anterior (878). Além disso, nota-se um aumento da atividade grevista na es-

9 "As teorias pessimistas acerca do enfraquecimento do trabalho nas mãos da globalização neoliberal precisam ser reconciliadas com as teorias otimistas a respeito de um novo transnacionalismo do trabalho. Integrando análises das interações entre o trabalho nacional com análises tanto do que está acontecendo dentro das fronteiras nacionais quanto o que se passa no nível global é uma maneira de fazer isto" (Evans, 2014, p. 274)

${ }^{10}$ Vale acrescentar que este novo campo investigativo apoia-se nos chamados estudos de história global do trabalho (Silver, 2003; Van der Linden, 2013), a fim de comparar estratégias auto-organizativas em diferentes contextos nacionais (Chun, 2009).

${ }^{11}$ Cf. artigo de Peter Evans neste dossiê. 
fera privada, em especial, no setor de serviços. Notoriamente, o setor de serviços acantona os trabalhadores mais jovens, os empregos pior remunerados, menos qualificados e com altas taxas de rotatividade da força de trabalho. Portanto, é razoável supor que este aumento das greves no setor de serviços esteja diretamente relacionado à crescente insatisfação do precariado com a fadiga do atual modelo brasileiro de desenvolvimento pós-fordista e financeirizado. Além disso, levando-se em conta a polarização político-eleitoral, experimentada pelo país em 2014, não seria nada surpreendente verificar que esta insatisfação em relação à estrutura social inviabiliza a reprodução do modo de regulação lulista.

Da mesma forma, o recente ciclo de greves políticas gerais nacionais, ocorrido na Espanha e em Portugal, foi caracterizado pela massiva presença de jovens trabalhadores desempregados ou subempregados, pertencentes aos movimentos "15-M" e "Que se lixe a Troika!”, somados à atuação dos movimentos de trabalhadores precarizados (Oficina Precária, Precários Inflexíveis) (Camargo, 2013; Dois, 2009; Pinto, 2011). Em inúmeras ocasiões, os protestos de rua protagonizados por estes jovens superaram em número as marchas organizadas pelos sindicatos oficiais, favorecendo ص a aproximação entre o tradicional sindicalismo సं português - em especial, aquele ligado à Conه্ঠ federação Geral dos Trabalhadores Portugueses (CGTP) - e os novos movimentos de jovens trabalhadores precarizados.

Trata-se de uma relação atravessada por diferenças problemáticas, que vão desde as orientações táticas existentes entre o a sindicalismo e os novos movimentos sociais,

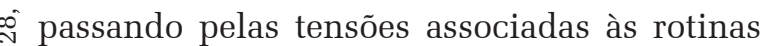
$\therefore$ burocráticas sindicais, até chegarmos aos estranhamentos ligados à diferença geracional. Apesar disto, esforços em favor de coalizões anti-austeridade ganharam corpo nos últimos anos, com flagrante sucesso em termos de coordenação do calendário de protestos.

Assim, novas dinâmicas da ação coleti- va têm se delineado em escala internacional no contexto da crise do modelo de desenvolvimento pós-fordista em escala global. De fato, em decorrência da descentralização da produção, da financeirização das empresas, da precarização das formas de contratação e da generalização da terceirização da força de trabalho, as formas tradicionais de auto-organização política dos trabalhadores, em especial os sindicatos, têm enfrentado enormes desafios ao redor do globo. O resultado da confluência de todas essas tendências tem sido o incremento do peso relativo do proletariado precarizado no interior das classes trabalhadoras de diferentes países, tanto no Norte quanto no Sul globais. A questão levantada pela emergência do que seria este precariado global é saber como essa fração de classe irá se comportar no devir das lutas sociais.

\section{PRECARIADO E MOVIMENTO SINDI- CAL NO SUL GLOBAL}

Entre as abordagens que emergiram nos últimos anos, no campo de estudos do trabalho global, para problematizar a ação política dos trabalhadores informais e precarizados, assim como sua relação com a nova regulação pósfordista (des)construída pela globalização capitalista, destaca-se o livro de Guy Standing, $O$ precariado: a nova classe perigosa (2013). Sem dúvidas, trata-se de um dos mais impactantes livros sobre o mundo do trabalho lançado nas últimas décadas. Na realidade, este livro, a partir de uma determinada perspectiva, traduz em dados o que seria o espírito de toda uma época: vivemos sob a sombra do "precariado", isto é, um grupo de pessoas despojadas de garantias trabalhistas, submetidas a rendimentos incertos e carentes de uma identidade coletiva enraizada no mundo do trabalho. Em larga medida, é da qualidade da ação coletiva desse grupo que depende o futuro dos movimentos sociais globais.

A descrição que Standing faz das razões pelas quais a globalização econômica, 
por meio da flexibilidade do trabalho, ampliou incessantemente o tamanho do precariado é verdadeiramente arrasadora, pois a mercantilização do trabalho, associada tanto ao aprofundamento da concorrência intercapitalista quanto à financeirização do meio ambiente empresarial, colocaria em risco o conjunto da reprodução social.

Em seu livro, Standing enfrentou os desafios levantados por Polanyi há exatos setenta anos. Além de criticar a liberdade de movimentos e a concentração dos capitais financeiros, ele denunciou os efeitos deletérios da submissão de parte substantiva do movimento sindical europeu e setores hegemônicos do mainstream político reformista e social-democrata a um modelo de desenvolvimento socialmente irresponsável e ecologicamente insustentável. No entanto, seu foco principal é o advento e o destino histórico do precariado como uma nova classe em transformação.

Apesar dos claros méritos do livro, estamos entre aqueles que consideram que um estudo dessa qualidade sempre estimulará o desejo de discutir e argumentar. Adiantamos que, ao contrário da maior parte dos exemplos e dados presentes no livro, cujo foco recai sobre as relações trabalhistas em países de capitalismo avançado, comentaremos a obra da perspectiva dos estudos das metamorfoses do capitalismo e da classe trabalhadora no chamado "Sul global".

Talvez isso seja de alguma valia ao debate. Afinal, acreditamos que Standing (2013) concentrou-se excessivamente na ampliação do precariado em países de capitalismo avançado, sobrando pouco espaço para a maior parte da força de trabalho mundial, que se encontra submetida a condições severamente piores de precariedade laboral do que aquelas encontradas na Europa ocidental. De fato, uma parte significativa das ameaçadoras relações sociais tão bem analisadas no livro parecem incrivelmente familiares à sensibilidade daqueles que se especializaram em pesquisar, por exemplo, a resiliência histórica do trabalho informal nas economias semiperiféricas.

Por essa razão, dentre as inúmeras possibilidades de interlocução com o livro, tentaremos nos concentrar em apenas duas variáveis do precariado pós-fordista, isto é, sua natureza de classe e seus padrões de mobilização coletiva. Standing compreende que o precariado não faz parte da classe trabalhadora. Ao contrário, ele constituiria uma classe social de novo tipo, produto das transformações decorrentes da globalização capitalista e das estratégias de flexibilização do trabalho em suas múltiplas dimensões. De certa maneira, o precariado seria o filho indesejado do casamento do neoliberalismo com a globalização do capital.

Essa união teria engendrado uma nova classe, formada, basicamente, por pessoas destituídas das garantias sociais relativas ao vínculo empregatício, à segurança no emprego, à segurança no trabalho, às formas de reprodução das qualificações, à segurança da renda e à falta de representação política. Tudo aquilo que configurou a robustez da cidadania salarial fordista na Europa e nos Estados Unidos após a Segunda Guerra Mundial e que estaria sendo negado à geração dos filhos dos baby boomers.

Em termos históricos, Standing (2003, p. 22-3) entende que o precariado afasta-se da classe trabalhadora, pelo fato de esta sugerir uma sociedade formada, majoritariamente, por "trabalhadores de longo prazo, em empregos estáveis de horas fixas, com rotas de promoção estabelecidas, sujeitos a acordos de sindicalização e coletivos, com cargos que seus pais e mães teriam entendido, defrontando-se com empregadores locais com cujos nomes e características eles estavam familiarizados".

Em nossa visão, essa definição aproxima-se mais do conceito de "salariado" - criado pelos economistas da Escola Francesa da Regulação e enriquecido por sociólogos críticos, como Castel (1998), por exemplo, para apreender o tipo de norma social de consumo própria ao modelo de desenvolvimento fordista - do que do conhecido conceito marxista de classe trabalhadora. Aliás, nunca é demais lembrar 
que, para Marx (2013), em decorrência da mercantilização do trabalho, do caráter capitalista da divisão do trabalho e da anarquia da reprodução do capital, a precariedade é parte constitutiva da relação salarial.

Nessa perspectiva, o atual aprofundamento da precarização laboral em escala global apoia-se no aumento da taxa de exploração da força de trabalho, tendo em vista, sobretudo, a espoliação dos direitos sociais associada à “acumulação mediante despossessão" (Harvey, 2004). Em todo caso, não parece razoável falar em uma relação de produção de novo tipo, capaz de produzir uma "nova classe". Antes, trata-se de um retrocesso, em termos civilizatórios, potencializado pelo longo período de acumulação desacelerada que se arrasta desde, ao menos, meados dos anos 1970, e cujos desdobramentos, em termos da deterioração do padrão de vida dos trabalhadores e assalariados médios, tornaram-se mais salientes após 2008.

Se, na Europa ocidental e nos Estados Unidos, décadas de institucionalização de direitos sociais mitigaram a condição estruturalmente precária do trabalho assalariado, por meio da integração da fração masculina, branca, adulta, nacional e sindicalizada da classe trabalhadora ao ciclo da transferência de parte dos ganhos de produtividade aos salários, a transformação de um longo período de cresciจ mento lento em uma crise econômica sistêmiФึ ca em escala global trouxe novamente à baila a precariedade como condição social inerente à fi mercantilização do trabalho.

A propósito, a ausência de um sentido de carreira, de identidade profissional segura e de direitos trabalhistas é um traço que, grosso modo, acompanhou a industrialização do Sul global: basta lembrarmos o apartheid sul-africano, a ditadura militar brasileira ou as maquilas mexicanas. No Brasil, a precariedade da reprodução da força de trabalho é uma característica estrutural do fordismo periférico, que continua presente ainda hoje. Para efeitos ilustrativos, entre 2003 e 2010, um período marcado por crescimento econômico com for- malização do emprego, a atual taxa de informalidade do trabalho no Brasil ainda era de 44\% (IBGE, 2010, p. 251). Vale lembrar que, no sul da Europa, mesmo após cinco anos de forte crise econômica, com ampliação do desemprego e precarização do trabalho, essa taxa gravita em torno de 20\% (Romanet, 2012).

Uma mirada na formação do precariado europeu, de uma perspectiva brasileira, talvez seja útil para problematizar aquela que constitui a grande contribuição de Standing (2013) ao debate público contemporâneo: o alerta sobre a natureza "perigosa", isto é, filo-fascista, dessa nova classe. De fato, o autor constrói, ao longo do livro, uma imagem do precariado como uma classe alienada, ansiosa, insegura, infantilizada, oportunista, cínica, passiva e detentora de um estado psíquico nebuloso. Não é de se estranhar, portanto, que, do ponto de vista político, o precariado seja considerado uma presa fácil dos apelos neopopulistas, e potencialmente hostil ao regime democrático.

Detenhamo-nos, por um instante, neste ponto, qual seja, a "política do precariado". Por um lado, se Standing (2103) nitidamente acerta ao destacar os jovens recém-chegados ao mercado de trabalho, especialmente os estagiários e operadores de telemarketing, como o grupo mais representativo entre os que irão desenvolver uma trajetória ocupacional frustrante e apartada daquela bem mais estável verificada por seus pais, por outro, sua caracterização a respeito da relação desses jovens com os sindicatos merece um olhar mais detido. Em suma, o autor identificou uma postura socialmente ressentida e politicamente antissindical por parte do precariado europeu.

A razão da hostilidade ao movimento trabalhista dever-se-ia, sobretudo, ao fato de os trabalhadores jovens, politicamente inexperientes e submetidos à precarização do emprego, considerarem praticamente impossível organizar-se sindicalmente nos locais de trabalho. Assim, o precariado associaria os sindicatos aos "privilégios" reservados aos assalariados mais velhos, que ainda desfrutam de 
alguma proteção social garantida pelas formas tradicionais de negociação coletiva.

Standing (2013) acaba por subestimar a capacidade de auto-organização do precariado, além de obnubilar uma visão mais totalizante das formas de representação política associadas aos interesses do precariado. Em suma, ele considera que, nas atuais condições, marcadas pela globalização capitalista e pelo enfraquecimento dos sindicatos e dos partidos social-democratas tradicionais, apenas como parte da governança das agências sociais e econômicas é que o precariado poderá ser bem representado. Para tanto, advoga que as esferas de formulação de políticas públicas devam ser democratizadas com a presença de representantes da "nova classe".

Não se trata de ser contra a democratização do aparelho de Estado. No entanto, se levarmos em conta a experiência brasileira recente, não percebemos nenhuma razão clara para que o precariado assuma a defesa da Renda Básica Universal como sua bandeira prioritária de mobilização. Na verdade, e esta é uma das principais lições das manifestações de Junho de 2013, a automobilização em defesa dos direitos da cidadania continua definindo o horizonte de intervenção política dos jovens trabalhadores precarizados no país. Se desejamos apreender a diversidade concreta de suas formas contemporâneas de auto-organização, limitar a ação coletiva desse grupo a essa pressão no campo de reformas das políticas públicas parece um tanto insuficiente. Esse é o argumento que desenvolveremos a seguir.

\section{JUVENTUDE TRABALHADORA PRECÁRIA, MOVIMENTO SINDICAL E AÇÃO COLETIVA NO BRASIL}

Ao elaborar seu diagnóstico sociológico e sua agenda política, Standing optou por afastar o precariado tanto dos demais grupos da classe trabalhadora quanto do movimento sindical. Se, como afirma o autor, os sindica- tos estão condenados ao desaparecimento, é evidente que eles não podem propor soluções capazes de fortalecer a universalização dos direitos sociais e enfrentar a precarização do trabalho. Mas, até que ponto a desconstrução analítica da relação entre o precariado, a classe trabalhadora e os sindicatos é empiricamente consistente? Como o precariado no Sul global tem se comportado em relação aos direitos sociais e ao sindicalismo?

A análise da relação entre o amadurecimento da experiência política de jovens trabalhadores precários e as dinâmicas recentes do sindicalismo no Brasil pode ser útil na tentativa de esboçar respostas a essas questões. Naturalmente, pode-se dizer que tais casos refletem a totalidade dessa relação. No entanto, eles podem ajudar a relativizar tanto a concentração dos exemplos, citados por Standing, em países capitalistas avançados quanto seu excessivo pessimismo relativo às inclinações autoritárias do precariado. Aqui, seria o caso de apontar os encontros e desencontros que marcam esta relação e que podem ser úteis para enriquecermos o debate acerca da natureza da política do precariado.

O primeiro caminho, com a marca do desencontro, trata da experiência do precariado e do sindicalismo durante as rebeliões de junho de 2013. Vários levantamentos indica$\mathrm{ram}^{12}$ que, em sua larga maioria, aqueles que estão nas ruas são jovens, universitários, têm emprego e ganham entre um e três salários mínimos (renda média familiar mensal). Assim, são jovens trabalhadores universitários que, parte do dia, trabalham e, parte do dia, estudam. Que, independentemente da formalização de seu trabalho, têm, em termos de entrada no mercado e em termos de rendimento, o que poderia se chamar de uma entrada subalterna neste mercado. São eles, não só, mas também, que questionam o preço dos transportes, cujos gastos drenam seus rendimentos, serviços públicos de saúde, porque têm de gastar com planos de saúde privados, gastos com a educação,

${ }^{12}$ Para mais detalhes, ver consolidação dos dados de diferentes fontes realizada por André Singer (2014). 
já que a maioria está em universidade privada, e por aí poderíamos seguir.

Portanto, as forças sociais do trabalho estavam ali presentes. Temos de pensar em toda a riqueza e complexidade dos processos de formação de classe (Thompson, 1987). Talvez, ao contrário do que se esperava. Afinal, aquela "geração neoliberal", diferente do que se previa em horizontes individualistas/apáticos/competitivos/fragmentados, agora "nas ruas e na luta", se assumia em suas demandas como uma "geração precária", assim como fizera aquela de 2005-06 na França.

Em uma cidade, dita de tantos acessos e possibilidades, que estimulou a imagem de maravilhosa sobre si mesma, como o Rio de Janeiro, por exemplo, com tantas obras impulsionadas pelos megaeventos e investimentos massivos em curso, pode-se entender como se articulam entrada precária no mercado de trabalho, baixos rendimentos, políticas de remoção, mercado imobiliário estratosférico, serviços ruins e repressão policial, em um cadinho bastante explosivo. E, aí, seria interessante começarmos a falar mais da qualidade de inserção destes contingentes, e não somente das cifras de sua inserção, que, obviamente, mascaram muito dos processos sociais concretos.

As forças sociais do trabalho, em seus 2 termos tradicionais, pensemos aqui em sindi於 catos e partidos, tiveram muita dificuldade de Фं lidar com este magma em seu jorro. Pode-se dizer que as forças sociais do trabalho tentaram lidar com esta pulsão plebeia de forma um tanS. to quanto tradicional. Uma massa fortemente . horizontalizada pela via das redes sociais, e is questionando as formas de representação, seja \& no parlamento, no sindicato ou no Diretório ণ Central dos Estudantes, e, jogada na ação direta, não parecia disposta a querer se submeter a muitos ditames oriundos daqueles que eram identificados como representando forças políticas tradicionais (Cohen e Santana, 2014).

Ela exporá a burocratização dos partidos e dos sindicatos. Como que a lembrá-las que, para além do aspecto institucional, um aspecto mais participativo, de movimento, precisa ser acionado sob o risco de enrijecimento. Harvey (2012), mais uma vez, nos lembra que é limitada a visão que contrapõe pura e simplesmente a organização horizontal à organização vertical. Em sua perspectiva, seria preciso pensar formas de articulá-las, ao invés de falarmos e partimos sempre das impossibilidades desta articulação.

Em meio aos protestos daquela conjuntura, foi marcada uma greve geral, pelas redes sociais, por cima e para além de sindicatos e centrais sindicais, em um verdadeiro desafio às formas de organização e representação existentes no mundo do trabalho. Só, aí, então, estas forças resolveram, de forma mais clara e explícita, tomar também as ruas, em um dia de paralisação que, acima de tudo, buscava esvaziar, em seu chamado, a greve geral, convocada sem as forças sociais do trabalho organizadas em agrupamentos tradicionais. Apesar de trazer uma centena de milhar às ruas, por todo o país, este dia nacional de luta, quando comparado às manifestações do período, ficou muito aquém, numericamente, não conseguindo empolgar as novas forças sociais do trabalho que reforçavam as outras manifestações.

Apesar de entender os limites experimentados por sindicatos e centrais sindicais (e isso se dá em escala global), perguntamo-nos se uma aproximação maior com as demandas desta grande parcela de jovens, que esteve e estava nas ruas, não seria possível? Será que a pauta do dia nacional de lutas incorporou, realmente, em forma e conteúdo, as demandas mais imediatas e cotidianas desta massa de jovens trabalhadores universitários precários nas ruas? ${ }^{13}$ Será que esta incorporação seria tão desestabilizadora assim, mesmo àqueles que apoiam o

${ }^{13}$ A pauta unitária das Centrais se posicionava, por exemplo, contra o PL 4330, da "terceirização" que retira direitos dos trabalhadores brasileiros e precariza, ainda mais, as relações de trabalho no Brasil; que as reduções de tarifa do transporte não fossem acompanhadas de qualquer corte dos gastos sociais; $10 \%$ do orçamento da União para a saúde pública; $10 \%$ do PIB para a educação pública, "verbas públicas só para o setor público"; fim do fator previdenciário; redução da Jornada de Trabalho para 40 horas sem redução de salários; reforma agrária; suspensão dos Leilóes de Petróleo. 
projeto no governo? Será que esta incorporação não teria auxiliado, no sentido de pressionar o governo, na direção dos avanços na questão social ligada ao mundo do trabalho?

O segundo caminho traz a marca do encontro, a partir da experiência dos operadores de telemarketing em São Paulo. O notável crescimento do telemarketing, em especial na cidade de São Paulo, não é nenhum segredo. Para ilustrar sua importância, bastaria dizer que, com cerca de 1,4 milhão de teleoperadores, essa indústria acantona um dos maiores contingentes ocupacionais do país, perdendo, apenas, para as empregadas domésticas (com cerca de 7,2 milhões de trabalhadoras) (Cavallini, 2013 e Codogno, 2013). Dispensável dizer que condições muito precárias de emprego prevalecem no call center. Exatamente porque tal indústria não necessita, em termos gerais, de uma força de trabalho especialmente qualificada, as empresas beneficiam-se de um regime de relações de trabalho apoiado em elevadas taxas de rotatividade.

Aliás, o ciclo ao qual o trabalhador está submetido é bastante conhecido pelas empresas: em geral, o teleoperador necessita de dois a três meses de experiência para se tornar proficiente no produto. Trata-se de um período estressante, pois o desempenho médio exigido dificilmente é alcançado pelo trabalhador ainda inexperiente. Após esses primeiros meses, o teleoperador encontra-se apto a alcançar as metas, advindo um período de, aproximadamente, um ano, ao longo do qual ele obtém certa satisfação residual em razão do domínio da atividade.

No entanto o endurecimento das metas, a rotinização do trabalho, o despotismo dos coordenadores de operação, os baixos salários e a negligência por parte das empresas quanto à ergonomia e à temperatura do ambiente promovem o adoecimento, alimentando o desinteresse pelo trabalho. Nesta fase, o teleoperador deixa de "dar o resultado", sendo demitido e substituído por outro, que recomeçará o mesmo ciclo. Evidentemente, a alta taxa de rotatividade do setor, de $42 \%$, produz um acentuado descon- tentamento entre os teleoperadores, em especial entre os mais experientes (DIEESE, 2014).

A despeito de seus notáveis esforços individuais em ascender profissionalmente, seja frequentando uma faculdade particular noturna (um terço do total de teleoperadores de nossa amostra declarou estar cursando o ensino superior), seja por meio das tentativas de progredir para funções superiores no interior da própria empresa, em raras ocasióes os teleoperadores aumentam, significativamente, seus salários ou incrementam suas condições de trabalho. E, como poderia ser diferente se, durante a última década, $94 \%$ dos empregos formais criados no país pagam até 1,5 salário mínimo (Pochmann, 2012)? O descontentamento observado durante as entrevistas só não foi maior porque o setor está em permanente renovação, por meio da chegada de grandes contingentes de trabalhadores jovens em busca do primeiro emprego no mercado formal de trabalho.

De fato, para muitas teleoperadoras, a sensação de progresso ocupacional encontra-se fortemente associada à transição da informalidade para a formalidade. No telemarketing, essas jovens perceberam a oportunidade tanto de 1) alcançar direitos trabalhistas, quanto de 2) terminar a faculdade particular noturna, que o trabalho doméstico, devido à incerteza dos horários, aos baixíssimos salários e à baixa intensidade dos direitos, é incapaz de prover. No entanto, o acúmulo de experiências com o regime de mobilização permanente da força de trabalho faz com que esses trabalhadores desenvolvam comportamentos críticos em relação às empresas. Esses comportamentos são a base instrumental para sua aproximação aos sindicatos.

De fato, o que aconteceria se, aos olhos do jovem trabalhador precário paulistano, em vez de representar os privilégios inalcançáveis da geração anterior, os sindicatos anunciassem a possibilidade de efetivar direitos sociais que foram negados a seus pais? Foi exatamente essa a realidade que verificamos ao analisar a relação dos teleoperadores com o movimento sindical na segunda metade dos anos 2000. Apesar 
de sua inexperiência política, esses trabalhadores buscavam, no sindicalismo, apoio para suas reivindicações trabalhistas. E, como poderia ser diferente se, no setor, tende a imperar a dura realidade dos baixos salários, da alta rotatividade, do adoecimento, do assédio moral etc.?

$\mathrm{O}$ aprofundamento da experiência com o regime de trabalho despótico da indústria do call center promoveu, não apenas comportamentos críticos em relação às empresas, como, também, desenvolveu formas embrionárias de consciência de classe, que foram elaboradas pelos sindicatos. Estes empreenderam um notável esforço a fim de se aproximar dos trabalhadores dessa indústria. Mapeando as características de gênero, raça, idade e orientação sexual, o movimento sindical no setor, em especial o Sindicato dos Trabalhadores em Telemarketing (Sintratel), reconfigurou sua agenda, diversificando-a a ponto de inovar em inúmeras frentes. Os principais sindicatos que atuam no setor de telemarketing decidiram participar da organização da Parada do Orgulho LGBT (sigla para lésbicas, gays, bissexuais, travestis, transexuais e transgêneros) de São Paulo, animando um dos blocos mais tradicionais do desfile (Braga et al, 2011).

Além de, há vários anos, destacar-se na organização e participação, por meio de suas م campanhas de sindicalização, da Parada do จे Orgulho LGBT de São Paulo, o Sintratel desenФิ volveu iniciativas junto à Secretaria de Direitos Humanos da Presidência da República, em fi conjunto com o Ministério Público do Trabalho,

\& Mundial, ocasião em que começou a organizar $\stackrel{\infty}{\sim}$ campanhas internacionais de solidariedade a

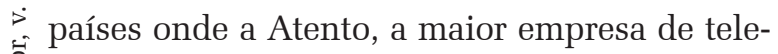
marketing do mundo, mantém operações.

O sucesso desse esforço pode ser medido pelo aumento do número de greves e paralisações de teleoperadores em São Paulo. De fato, praticamente inexistentes há dez anos, os movimentos grevistas no setor desenvolveram- se a ponto de se destacar nas greves nacionais bancárias. Entre 2008 e 2012, ocorreram quatro greves nacionais dos trabalhadores bancários com efetiva participação dos teleoperadores. Apenas em 2012, a greve bancária atingiu um pico de 280 mil trabalhadores parados, prolongando-se por dez dias (DIEESE, 2013).

\section{CONSIDERAÇÕES FINAIS}

Nossa conclusão é que, quer da perspectiva dos sindicatos, quer do ponto de vista dos jovens trabalhadores precarizados, certa atitude colaborativa tem, entre encontros e desencontros, ainda que lentamente, evoluído de parte a parte. E, se buscam ampliar sua capacidade de representação, organização e mobilização, se observado o desenvolvimento histórico, não parece haver mesmo outra alternativa.

Este não tem sido um caminho fácil. Ora converge, ora bifurca. Estruturas e práticas tradicionais, baseadas em longo assentamento em um perfil determinado de mercado de trabalho e de trabalhadores que lhes correspondem, são postas à prova, questionadas, reconfiguradas em termos de formas de organização e mobilização, de prática política, de temas e agendas. Nada está definido de antemão, há um presente e um futuro em disputa.

Não devemos nos orientar analiticamente por fatalismos e naturalizações oriundas de leituras deterministas das posições sociais dos atores na estrutura social e produtiva, bem como de suas decorrências políticas. Estreita muito a angulação ter expectativas de essências ou tendências fascistas ou revolucionárias nesta juventude precária. As construções e projetos políticos, sociais e societários definem e definirão estes horizontes.

Os jovens trabalhadores precarizados brasileiros lutam para efetivar seus direitos sociais. Eles olham para o futuro com certo otimismo, ainda que questionador. No entanto, não há, evidentemente, hostilidade ao regime democrático. Como se diz, querem "mais e melhor democra- 
cia”. Muito menos nutrem agressividade definitiva e intransponível contra o movimento sindical. Aliás, apesar de uma dificuldade de interação e uma separação extrema inicial, é mais fácil perceber uma relação de mútuo reconhecimento desenvolvendo-se lentamente.

Os jovens trabalhadores, cada dia mais submetidos a condições precárias de vida e trabalho, reconhecem nos sindicatos potenciais aliados na luta pela ampliação de direitos sociais. O movimento sindical identifica nestes jovens trabalhadores um setor incontornável no fortalecimento de suas pautas mais fundamentais, cada vez mais e forçosamente generalizadas, e percebe nele potencial de renovação, capilaridade e radicalidade, que - ainda que ameacem e possam desestabilizar o status quo sindical tradicional, estruturas e práticas estabelecidas - lhe são indispensáveis em sua lida com o mundo do trabalho contemporâneo.

Não nos parece o caso de insistir em uma contradição insuperável entre os interesses sindicais e as necessidades da juventude precarizada. Ao contrário, é perfeitamente possível identificar mais convergências que divergências em termos de interesses democráticos e de participação: para além dos exemplos citados acima, bastaria lembrarmos a vitória eleitoral do partido Podemos na Espanha. Nascido dos Indignados do $15 \mathrm{M}$, em poucos meses de existência, o partido elegeu cinco deputados para o Parlamento Europeu nas eleições de 25 de maio de 2014 e, em 24 de maio de 2015, saiu-se vitorioso, obtendo massiva votação nas eleições municipais e regionais, batendo uma hegemonia de décadas dos partidos tradicionais.

Finalmente, devemos dizer que estamos convencidos de que é da qualidade da ação coletiva desse jovem trabalhador precário, no Brasil e no mundo, que dependem, cada vez mais, as dinâmicas da ação coletiva e o futuro dos movimentos sociais. Recebido para publicação em 11 de maio de 2015
Aceito em 05 de agosto de 2015

\section{REFERÊNCIAS}

ALEGRETTI, Laís; WARTH, Anne. Criação de emprego em 2013 é a menor em 10 anos. O Estado de S. Paulo, 21 jan. 2014.

ANTUNES, Ricardo (org.). Riqueza e miséria do trabalho no Brasil III. São Paulo: Boitempo, 2014.

. O continente do labor. São Paulo: Boitempo, 2011.

; BRAGA, Ruy. Los días que conmovieron a Brasil.

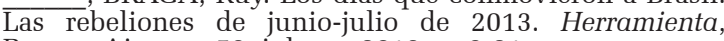
Buenos Aires, n. 53, jul.ago. 2013. p. 9-21.

AGARWALA, Rina. Informal Labor, Formal Politics, and Dignified Discontent in India. Cambridge: Cambridge University Press, 2013.

Auditoria Cidadã da Dívida, 2014.

BICHIR, Renata Mirandola. O Bolsa Família na berlinda? Os desafios atuais dos programas de transferência de renda. Novos Estudos Cebrap, n. 87, 2010.

BIELER, Andreas. Transnational Labour Solidarity in (the) Crisis. Global Labour Journal, Hamilton, v. 5, n. 2, 2014.

BIELER, A., CICCAGLIONE, B., HILARY, J. and LINDBERG, I. (eds.). Free trade and transnational labour. Londres: Routledge, 2014.

BIELER, A.; LINDBERG, I. Global restructuring, labour and the challenges for transnational solidarity. Londres: Routledge, 2010.

BRAGA, Ruy. A pulsão plebeia: trabalho, precariedade e rebeliões sociais. São Paulo, Alameda, 2015.

As jornadas de junho no Brasil: crônica de um mês inesquecível. Observatorio Social de América Latina, Buenos Aires, n. 34, nov. 2013. p. 51-61.

A política do precariado: do populismo à hegemonia lulista. São Paulo: Boitempo, 2012.

et al. Social movement unionism and neoliberalism in São Paulo, Brazil: shifting logics of collective action in telemarketing labor unions. Societies without Borders, v. 6, n. 1, 2011. p. 73-101.

BURAWOY, Michael. Facing an unequal world. Current Sociology, Madri, v. 63, n. 1, 2014a, p. 5-34.

. Marxismo sociológico. São Paulo: Alameda, 2014b.

From Polanyi to Pollyanna: the false optimism of global labor studies. Global Labour Studies, Hamilton, v. 1, n. 2, 2010a.

. O marxismo encontra Bourdieu. Campinas: Editora da Unicamp, 2010b.

CABANES, Robert et al. (orgs.). Saídas de emergência: ganhar/perder a vida na periferia de São Paulo. São Paulo: Boitempo, 2011.

CASTEL, Robert. As metamorfoses da questão social: uma crônica do salário. Petrópolis: Vozes, 1998.

CAVALLINI, Marta. Telemarketing emprega 1,4 milhão no país. O Globo, Rio de Janeiro, 7 out. 2012.

CHIBBER, Vivek. Into the fold: labor's incorporation into the Indian Political Economy. In GOLFIELD, Michael; BANERJEE, Debdas (eds.). Labour, globalization, and the State. Nova Iorque, Routledge, 2007.

CHUN, Jennifer Jihye. Organizing at the margins. Ithaca: Cornell University, 2009.

COHEN, Y: SANTANA, M.A. Du Brésil au monde et retour: mouvements sociaux localisés et en résonance, Brésil(s), v. 7, 2015, p. 103-122. 
DEPARTAMENTO INTERSINDICAL DE ESTATÍSTICA E ESTUDOS SOCIOECONÔMICOS (Dieese). Rotatividade setorial: dados e diretrizes para a ação sindical. São Paulo, Dieese, 2014.

. Estudos e Pesquisas. Balanço das Greves em 2012, n. 66, maio 2013a.

. Estudos e Pesquisas. Balanço das negociações dos reajustes salariais de 2012, n. 64, mar. 2013b.

ESTANQUE, Elísio. Entre a fábrica e a comunidade: subjectividades e práticas de classe no operariado do calçado. Porto: Afrontamento, 2000.

; COSTA, Hermes A. Labour relations and social movements in the $21^{\text {st }}$ century. In: ERASGA, Denis (ed.). Sociological Landscapes: Theories, Realities and Trends. Rijeka, Intech, 2012.

(orgs.). Revista Crítica de Ciências Sociais. Trabalho, precariedade e rebeliões sociais, Coimbra, $\mathrm{n}$. 103,2014

O sindicalismo português e a nova questão social: 'crise ou renovação? Coimbra: Almedina, 2011.

; SOEIRO, José. The new global cycle of $\overline{\text { protest }}$ and the portuguese Case. Journal of Social Science Education. Bielefeld, v. 12, n. 1, 2013. p. 31-40.

EVANS, Peter. National movements and transnational connections: global labor's evolving architecture under neoliberalism. Global Labour Journal, Hamilton, v. 5, n. 3, 2014 .

Is it labor's turn to globalize? Twenty-First Century opportunities and strategic responses. Global Labour Journal, Hamilton, v. 1, n. 3, 2010. p. 352-79.

. Is an alternative globalization possible? Politics $\mathcal{\sigma}$

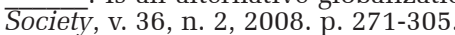

FLYNN, Greg; O'BRIEN, Robert. An internationalist western labour response to the globalization of India and China. Global Labour Journal, Hamilton, v. 1, n. 1, 2010.

HARRISS, J. Globalizations(s) and labour in China and India: introductory reflection. Global Labour Journal, Hamilton, v. 1, n. 1, 2010.

HARROD, J., O'BRIEN, R. (eds.). Global Unions: theory and strategies of organised labour in the global political economy. Londres e Nova Iorque: Routledge, 2002.

L $\mathrm{H}$ HARVEY, David. O "novo" imperialismo: sobre rearranjos 5 espaciotemporais e acumulação mediante despossessão.

N Revista Margem Esquerda, n. 5, 2004

D HOLLWAY, Wendy; JEFFERSON, Tony. Doing qualitative is research differently: free Association, Narrative and the \& Interview Method. Londres, Sage, 2005.

ó INSTITUTO BRASILEIRO DE GEOGRAFIA E i⿱ IN ESTATÍSTICA (IBGE). Estudos e Pesquisas. Informação 2. demográfica e socioeconômica, Brasília, n. 27, 2010.

ผ \& (Ipea). Comunicados do Ipea. Distribuição funcional da - renda pré e pós-crise internacional no Brasil, Brasília, $n$. $\stackrel{\infty}{\sim} 47,5$ maio 2010

JENKINS, R.; PEARSON, R.; SEYFANG, G. (eds). Corporate of responsibility and labour rights: Codes of Conduct. Londres: Earthscan, 2002.

कึ LEITE, Jorge et al. Austeridade, reformas laborais e - desvalorizacão do trabalho. In: CENTRO DE ESTUDOS SOCIAIS (CES). A anatomia da crise: identificar os o problemas para construir as alternativas $\left(1^{\circ}\right.$ relatório, $\because$ preliminar, do Observatório sobre Crises e Alternativas). Coimbra, CES-UC, 2014. No prelo.

ङ LIMA, Maria da Paz Campos; ARTILES, Antonio Martin.
Descontentamento na Europa em tempos de austeridade. Revista Crítica de Ciências Sociais, Coimbra, n. 103, maio 2014. p. 137-72.

LOUÇÃ, João Carlos. Call centers: trabalho, domesticação, resistências. Lisboa: Deriva, 2014.

MARX, Karl. O capital. Crítica da economia política. Livro I: O processo de produção do capital. São Paulo: Boitempo, 2013.

MATOS, José Nuno; DOMINGOS, Nuno; KUMAR, Rahul (Orgs.). Precários em Portugal: entre a fábrica e o "call center". Lisboa: Edições 70, 2011.

MONTEIRO, Bruno. Frágil como o mundo: etnografia do cotidiano operário. Lisboa: Afrontamento, 2014.

MOODY, Kim. Towards an International Social-Movement Unionism. New Left Review, n. 225, 1997.

MUNCK, Ronaldo. Globalization and the Labour Movement: Challenges and Responses. Global Labor Journal, Hamilton, v. 1, n. 2, 2010.

Globalisation and labour: the new "great transformation”. Londres: Zed Books, 2002.

NOWAK, Jörg; GALLAS, Alexander. Mass Srikes against austerity in Western Europe: a strategic assessment. Global Labour Journal, Hamilton, v. 5, n. 3, 2014.

OLIVEIRA, Francisco de; BRAGA, Ruy; RIZEK, Cibele S. (Orgs.). Hegemonia às avessas: economia, política e cultura na era da servidão financeira. São Paulo: Boitempo, 2010.

ORTIZ, Isabel et al. World Protests 2006-2013. Initiative for Policy Dialogue, Nova York, Friedrich-Ebert-Stiftung, set. 2013.

PARET, Marcel. Borders and exploitation: migrant labor systems in California and South Africa. Berkeley Journal of Sociology, v. 55, 2011.

PINTO, Ana Filipa. À Rasca: o retrato de uma Geração. Lisboa: Planeta, 2011.

POCHMANN, Marcio. Nova classe média? O trabalho na base da pirâmide salarial brasileira. São Paulo: Boitempo, 2012 .

POLANYI, Karl. A grande transformação. Rio de Janeiro: Campus, 2000.

PORDATA. Taxa de crescimento real do PIB per capita na Europa. Pordata. Disponível em:<http:// www.pordata.pt/Europa/Taxa+de+crescimento + real+do+PIB + per+capita-1533> Acesso em: 9 set. 2014.

REGO, Walquíria Leão; PINZANI, Alessandro. Vozes do Bolsa Família: autonomia, dinheiro e cidadania. São Paulo: Editora Unesp, 2014.

RIZEK, Cibele S. Gerir a pobreza? Novas faces da cultura nos territórios da precariedade. In: TORRES, Ana Clara R.

VAZ, Lilian Fessler; SILVA, Maria Lais Pereira da (Orgs.). Leituras da Cidade. Rio de Janeiro: Letra Capital, 2012a.

Trabalho, moradia e cidade: zonas de indiferenciação. Revista Brasileira de Ciências Sociais, v. $27,2012 b$

RODRIGUES, Sara; CAETANO, Emília. Dez minutos... e adeus! Visão, Paço de Arcos, n. 1.094, 20 fev. 2014.

ROMANET, Virginie de. Portugal: les conséquences dramatiques de l'austérité imposée par la Troïka. Comité pour l'Annulation de la Dette du Tiers Monde, 14 mar. 2012. Disponível em: <http://cadtm.org/Portugal-Lesconsequences $>$. Acesso em: 26 ago. 2014.

ROMBALDI, Maurício. O transnacional diante das fronteiras nacionais: ação sindical e condições sociais de acesso aos espacos sindicais internacionais. Tese de Doutorado em Sociologia, Universidade de São Paulo, 2009. 
SANTANA, M. A. Labor, workers, and politics in contemporary Brazil:1980 2010. In:Peilin Li; MKGorshkov; Celi Scalon; K L Sharma. (Org.). Social Stratification in the BRIC Countries: Change and Perspective. 1ed.: World Scientific Publishing Co, 2012, v. 1, p. 87-110.

PERES, I. Capitalismo, cidade e política na perspectiva de David Harvey. Sociologia \& Antropologia, v. 3, p. 151-174, 2013

SANTOS, Boaventura de Sousa. Para além do pensamento abissal: das linhas globais a uma ecologia de saberes. Novos Estudos Cebrap, São Paulo, n. 79, nov. 2007. p. 71-94.

. SANTOS, Boaventura de Sousa; COSTA, Hermes. Para ampliar o cânone do internacionalismo operário. In SANTOS, Boaventura de Sousa Santos (org.). Trabalhar o mundo. Os caminhos do novo internacionalismo operário. Porto: Edições Afrontamento, 2004.

SEIDMAN, Gay. Beyond the Boycott. Labor rights, human rights and transnational activism. Nova Iorque: Russell Sage Foundation, 2008.

SILVER, Beverly. Forces of labor: workers' movements and globalization since 1870. Cambridge: Cambridge University Press, 2003.

SINGER, André. Quatro notas sobre as classes sociais nos dez anos do lulismo. In: FUNDACC̃̃O PERSEU ABRAMO; FUNDAÇÃO FRIEDRICH EBERT (orgs.). Classes? Que classes? São Paulo, Fundação Perseu Abramo/ Fundação Friedrich Ebert, 2014

SOEIRO, José. A formação do precariado: transformações no trabalho e mobilizações de precários em Portugal. Coimbra, Tese de Doutorado em Sociologia, FEUC, 2015.
STANDING, Guy. A Precariat Charter: From Denizens to Citizens. Londres, Bloomsbury, 2014.

O precariado: a nova classe perigosa. São Paulo: Autêntica, 2013.

TAIT, V. Poor Workers' Unions: rebuilding labor from below. Cambridge: South End Press, 2005.

TARROW, S. Poder em movimento: movimentos sociais e confronto político. Petrópolis, Vozes, 2009.

THOMPSON, E.P. A formação da classe operária inglesa. v. 1. Paz e Terra, Rio de Janeiro, 1987.

VAN DER LINDEN, Marcel. Trabalhadores do mundo: ensaios para uma história global do trabalho. Campinas: Editora da Unicamp, 2013. 2003.

Transnational labour history. Aldershot, Ashgate,

WATERMAN, Peter. Needed: a global labour charter movement. [Mimeo], 2008.

Trade union internationalism in the age of Seattle. Antipode, v. 33, n. 3, p. 312-336, jul. 2001.

WEBSTER, E.; LAMBERT, R.; BEZUIDENHOUT, A. Grounding globalization: labour in the age of insecurity. Oxford: Blackwell, 2008. 


\section{DYNAMICS OF COLLECTIVE ACTIONS IN CONTEMPORARY BRAZIL: agreements and disagreements between unionism and the youth worker force}

\author{
Ruy Braga \\ Marco Aurélio Santana
}

Taking into account the traditional Unions' role in the conflict organization and mobilization in the Brazilian society, the article associates the social classes reconfiguration, contemporary social uneasiness and their impacts upon Brazilian Unionism. The main emphasis on Unions' role is related to the hypothesis that the different responses from Unions to this new scenario is a privileged opportunity to observe the current social classes reconfiguration during a crisis period and the resulting dynamics of collective action.

KeYwORDs: Work. Workers. Youth. Unions. Collective Action

\author{
DYNAMIQUES DE L'ACTION COLLECTIVE \\ AU SEIN DU BRÉSIL CONTEMPORAIN: \\ Convergences et divergences entre le syndicalisme \\ et les jeunes travailleurs
}

\author{
Ruy Braga \\ Marco Aurélio Santana
}

Compte tenu de la place traditionnelle occupée par les syndicats en tant que moyen d'organisation et de résolution des conflits dans la société brésilienne, cet article se propose d'articuler la reconfiguration des classes sociales au sein du Brésil contemporain, ainsi que les manifestations actuelles de l'inquiétude sociale et la situation des syndicats face à cette nouvelle configuration. L'accent mis tout particulièrement sur le rôle des syndicats dans cette nouvelle conjoncture mondiale part du principe que les différentes réponses des syndicats nationaux face à l'avènement du rôle politique de la jeunesse travaillant dans des conditions précaires de vie et de travail sont une excellente occasion pour observer les reconfigurations actuelles des paramètres de classe dans le contexte d'une crise.

Mots-CLÉs: Travail. Travailleurs. Jeunesse. Syndicats. L'action collective.

Marco Aurélio Santana - Doutor em Sociologia. Professor do Departamento de Sociologia e do Programa de Pós-Graduação em Sociologia e Antropologia do IFCS/UFRJ. Pesquisador do Núcleo de Estudos Trabalho e Sociedade (NETS-UFRJ). Tem experiência na área de Sociologia, com ênfase em Sociologia do Trabalho, atuando principalmente nos seguintes temas: Trabalho, Trabalhadores, Lutas sociais e Ditadura Militar. Publicações recentes: Bravos Companheiros: comunistas e metalúrgicos no Rio de Janeiro (1945-1964) (Rio de Janeiro, 7Letras, 2012); Partidos e trabalhadores na transição democrática: a luta pela hegemonia na esquerda brasileira. Revista Dados (2012); The dilemmas of the new unionism in Brazil: breaks and continuities. Latin American Perspectives (2014), em co-autoria com Ricardo Antunes.

Ruy Braga - Doutor em ciências sociais pela Universidade Estadual de Campinas e professor do Programa de Pós Graduação em Sociologia da Universidade de São Paulo (USP) onde coordena o Centro dos Estudos dos Direitos da Cidadania (Cenedic-USP). Tem experiência na área de Sociologia, com ênfase em Sociologia do trabalho, atuando principalmente nos seguintes temas: classe trabalhadora, sindicalismo e movimentos sociais. Publicações recentes: A política do precariado: do populismo à hegemonia lulista (São Paulo: Boitempo, 2012) e A pulsão plebeia: trabalho, precariedade e rebeliões sociais (São Paulo: Alameda, 2015). 